\title{
Bioflocculation of Basic Dye onto Isolated Microbial Biopolymers
}

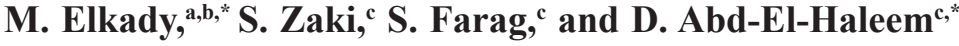 \\ ${ }^{a}$ Chemical and Petrochemical Engineering Department, \\ Egypt-Japan University of Science and Technology, \\ New Borg El-Arab City, Alexandria 21934, Egypt \\ 'Fabrication Technology Department, Advanced Technology \\ and New Materials Research Institute (ATNMRI), \\ City of Scientific Research and Technological Applications, \\ New Borg El-Arab City, Alexandria 21934, Egypt \\ 'Environmental Biotechnology Department, Genetic \\ Engineering and Biotechnology Research Institute, City \\ of Scientific Research and Technological Applications, \\ New Borg El-Arab City, Alexandria 21934, Egypt
}

doi: 10.15255/CABEQ.2016.1031

Original scientific paper Received: November 6, 2016 Accepted: July 30, 2017

Three purified biopolymers isolated from Bacillus velezensis (40B), Bacillus mojavensis (32A) and Pseudomonas (38A) strains were evaluated for dye decolourization as bioflocculants. The decolourization capacity of the three polymers was inspected using C.I 28 basic yellow dye as hazardous pollutant. The chemical compositions of these purified biopolymers were considered by HPLC and FTIR spectrum. The decolourization efficiency of the three purified biopolymers was determined using both real dye polluted wastewater (discharged from AKSA EGYPT acrylic fibres industry) and simulated synthetic wastewater. The maximum decolourization efficiencies of the purified biopolymers of the three studied strains (40B), (32A) and (38A) were 91, 89 and $88 \%$, respectively. The equilibrium of dye sorption process onto biopolymers was described using Langmuir isotherm equation. However, its kinetics follows the pseudo second order model. The thermodynamic examination investigated the exothermic and spontaneous nature of the decolourization process using the purified biopolymers.

Key words:

bioflocculants, biopolymer characterization, dyes decolourization, theoretical modelling

\section{Introduction}

Pollution monitoring reports have been issuing warnings due to the emission of many pollutants confronting contemporary society that urges dedication in environmental remediation researches. Coloured wastewater has been incremented as a result of dye production, and also as a consequence of its use in several industries. It is stated in the literature that 100,000 varieties of dyes are commercially available, with over $7 \cdot 10^{5}$ tons of dyes manufactured every year ${ }^{1}$. Practical pollution reports estimate that $2 \%$ of the annually produced dyes are released from the manufacturing operations effluent, while textile and related industries discharge almost $10 \%$ annually ${ }^{2}$. Discarding of untreated coloured effluents to the surroundings frequently causes coloured water bodies, causing chronic and acute toxicity. The re-oxygenation capacity of the

"Corresponding authors: marwa.f.elkady@gmail.com,

abdelhaleemm@yahoo.de; Tel.: +034593414 receiving water could be limited by the untreated effluent, which could also cut-off the sunlight that in turn disturbs the photosynthetic activities in the aquatic system ${ }^{3}$. Therefore, the environmental protection agencies call it as mandatory to treat dye bath effluents prior to discharging them into the surrounding aquatic systems or planning any reuse $\mathrm{e}^{4}$. Coloured effluents contaminated with dyes are usually treated with several physicochemical de-colourization processes, such as coagulation, precipitation, ozonation, photo-catalysis ${ }^{5,6}$, irradiation, and filtration ${ }^{7}$. Among these technologies, none has appeared as a panacea owing to high costs, low efficiency, and limited versatility ${ }^{8}$. Adsorption process is one of the most favoured and potent decolourization techniques that involves phase transfer of dye ions onto an adsorbent, leaving behind the clear effluent. Utilization of natural resources biomaterials as low-cost sorbents derived from carbonaceous materials (such as wood, peat, rice husk, and coconut shell) ${ }^{9}$, raw agricultural wastes (such as bagasse, 
peel sudanese and orange peels $)^{10}$, solids from industrial wastes (such as fly ash and metal hydroxide sludge), and natural materials (such as clays, zeolites, siliceous materials) have been explored as sorbent materials for dye adsorption. However, the application of these sorbent materials in the dye adsorption processes, generates substantial quantities of sludge as solid wastes which are difficult to dispose. In this context, the biosorption process employing biodegradable biopolymers and non-viable microbial (fungi, algae and bacteria) biomass has been considered the most sustainable technology which represents an environmentally friendly and competitive alternative $\operatorname{cost}^{11}$. More than sixty bioflocculant-producing bacteria have been isolated from different resources, such as soil and wastewater ${ }^{12}$. Bioflocculants are essentially polymers produced by microorganisms, their flocculating activities being dependent on the flocculants properties. While most bioflocculants are composed of polysaccharides and proteins, the components and structures of bioflocculants are complex as different organisms produce various bioflocculants with diverse properties.

Biosorption onto bioflocculants is described generally as a metabolism independent mechanism that involves binding of impurities to the cell membranes surfaces by physical attraction, ion exchange, electrostatic interaction, and chemical precipitation. In several cases, the contaminants may be suppressed within the cells. Additionally, the bridging mechanism plays a significant role in flocculating organic particles in wastewater and yeast cells ${ }^{13}$. Charge neutralization takes place when flocculants have opposite charge compared to particles charge. As most bioflocculants and particles are negatively charged, charge neutralization seldom occurs in the bioflocculation process. The materials to be used as biosorbents for dye removal should meet the following criteria: (a) low cost and abundant supply, (b) high rates and capacity for sorption, (c) applicable to waste solutions containing a variety of dye types, and (d) capability to withstand co-pollutants, such as salts, heavy metals and other conditions of wastewater ${ }^{14}$.

Although most bioflocculants can be utilized to flocculate kaolin suspension, they show different flocculation ability for colloids and particles in aqueous solution, such as organic solids and oil emulsion. It is noteworthy that bioflocculant utilization for flocculation of soluble substances such as dyes, has seldom been reported in literature. The ability of three innovative Egyptian isolated bioflocculants, identified as Bacillus velezensis, Bacillus mojavensis, and Pseudomonas for kaolin flocculation was reported in two earlier publications ${ }^{15-17}$. Subsequent experiments revealed that these biofloc- culants were characterized by their large flocculation efficiencies for kaolin suspensions. Consequently, the possibility of extending the application of these novel Egyptian isolated bioflocculants for uptake of very recalcitrant Textile Methine dyes, such as C.I 28 basic yellow dye, will be explored in this investigation. According to design and operation of dye biosorption systems, the specific objectives of this investigation were to: (i) examine the ability of these innovative Egyptian isolated bioflocculants for C.I 28 basic yellow decolourization from real and synthetic waste solutions, and assess the applicability of different equilibrium isotherm models for the basic dye biosorption using the isolated and purified biopolymers ${ }^{17}$.

\section{Materials and methods}

\section{Materials and adsorbate solution}

The decolourization efficiency of the three purified biopolymers was tested using real dye contaminated wastewater supplied from the discharge of AKSA EGYPT acrylic fibre industry at 4Th industrial zone, New Borg El-Arab City, Alexandria, Egypt. The real wastewater consisted of a mixture of dyeing and finishing steps. This polluted wastewater had a pale yellow colour and was contaminated mainly with C.I basic yellow 28. On the other hand, the basic yellow dye (C.I. 28, purity $99 \%$ ) was provided by Ciba Specialty Chemicals Inc. to be utilized as soluble adsorbate as synthetic waste solution.

\section{Cultivation of microorganisms and bioflocculants production}

Three different isolated microorganisms of $\mathrm{Ba}$ cillus velezensis ${ }^{15}$, Bacillus mojavensis ${ }^{16}$ and Pseudomonas $^{17}$ were cultured and characterized as bioflocculants for basic yellow dye removal. These sorbent-producing microorganisms were collected from different Egyptian ecosystems, as follows: Qarun Lake (Fayoum Oasis), salt production pond (Alexandria), and activated sludge gathered from industrial wastewater plant (Burg El-Arab, Alexandria), respectively.

Concerning the production of the bioflocculants, each isolated bacteria strain was inoculated separately into a $250 \mathrm{~mL}$ flask containing $100 \mathrm{~mL}$ seeding medium, and cultivated at $30{ }^{\circ} \mathrm{C}$ for $24 \mathrm{~h}$ at $200 \mathrm{rpm} .4 \mathrm{~mL}$ from each culture was injected into another $250-\mathrm{mL}$ reagent bottle containing $100 \mathrm{~mL}$ fermentation medium. The production media was composed mainly from $20 \mathrm{~g} \mathrm{~L}^{-1}$ of L-glutamic acid, $7 \mathrm{~g} \mathrm{~L}^{-1}$ of $\mathrm{NH}_{4} \mathrm{Cl}, 0.5 \mathrm{~g} \mathrm{~L}^{-1}$ of $\mathrm{K}_{2} \mathrm{HPO}_{4}, 0.5 \mathrm{~g} \mathrm{~L}^{-1}$ of $\mathrm{MgSO}_{4}, 40 \mathrm{mg} \mathrm{L}^{-1}$ of $\mathrm{FeCl}_{3}, 150 \mathrm{mg} \mathrm{L}^{-1}$ of $\mathrm{CaCl}_{2}$ 
and $140 \mathrm{mg} \mathrm{L}^{-1}$ of $\mathrm{MnSO}_{4}$ dissolved into double distilled water. The initial $\mathrm{pH}$ of the media was adjusted around value 7 using diluted $\mathrm{NaOH}$ solution. The bioflocculant was produced from each strain by shaking the flasks at $30{ }^{\circ} \mathrm{C}$ and $200 \mathrm{rpm}$ for $24 \mathrm{~h}$. The cell-free supernatants that include the liquid bioflocculants of the three different isolated strains were refrigerated at $4{ }^{\circ} \mathrm{C}$ to be purified and utilized for the dye biosorption process ${ }^{15-17}$.

\section{Purification of bioflocculants}

In order to purify the three isolated biopolymers, the suggested methodology established in our last published research work $^{16}$ was utilized. The stored cell free supernatants of the three strains $B a$ cillus velezensis, Bacillus mojavensis and deionized Pseudomonas were concentrated separately to 0.2 volumes using rotary evaporator and dialyzed overnight at $4{ }^{\circ} \mathrm{C}$ in water. Three volumes of frozen ethanol anhydrous $\left(4{ }^{\circ} \mathrm{C}\right)$ were added to the broth for each strain. The yielded precipitate from each strain was redissolved in deionized water followed by the addition of $10 \%$ cetylpyridinium chloride (CPC) under continuous stirring for 4 hours. The resultant precipitate was collected from each strain by centrifugation (5000 rpm, $15 \mathrm{~min}$ ) and dissolved in 0.5 $\mathrm{M} \mathrm{NaCl}$. Then, three volumes of frozen ethanol anhydrous $\left(4^{\circ} \mathrm{C}\right)$ were added to each strain to attain the precipitate was washed using $75 \%$ ethanol and lyophilized to acquire purified biopolymer from each strain.

\section{Purified bioflocculants characterization}

The protein content of bioflocculants was determined according to Bradford's method ${ }^{18}$. Total sugars were estimated using phenol-sulfuric acid reaction ${ }^{19}$. Sugars and amino acids composition were established using amino acid analyzer ${ }^{20}$ and high-performance liquid chromatography (HPLC) analysis, respectively. Furthermore, the main function groups of each bioflocculant were determined using Fourier transform infrared (FTIR) spectrophotometer (Shimadzu FTIR-8400 S), and scanned over a wave number range of 4,000 to $500 \mathrm{~cm}^{-1}$.

\section{Biosorption process}

The soluble basic yellow dye sorption affinity of the three purified biopolymers extracted from the three isolated Egyptian strains (Bacillus velezensis, Bacillus mojavensis, and Pseudomonas) was monitored using jar test batch technique. The yellow dye decolourization efficiency of the three isolated biopolymers was determined using both real dye polluted wastewater (discharged from AKSA EGYPT acrylic fibres industry) and simulated synthetic wastewater. Generally, for all biosorption systems, a specific weight from each purified biopolymer was mixed separately with $100 \mathrm{~mL}$ of dye solution of known concentration and $\mathrm{pH}$ into $500-\mathrm{mL}$ glass bottles. This reaction mixture was mixed rapidly at $230 \mathrm{rpm}$ for $2 \mathrm{~min}$, followed by slow mixing at 80 rpm for 3 min using Laboratory Flocculator (Flocumatic 6 PLAZAS/sample, Spain), and left at the steady state for $3 \mathrm{~min}$ at $25{ }^{\circ} \mathrm{C}$. After finishing the biosorption process, the samples were collected from the flasks and the dye solutions were separated from the sorbent by centrifugation. The absorbance of the remaining dye solution was measured at $438 \mathrm{~nm}$ using UV spectrophotometer $(7230 \mathrm{G}$, Shanghai, China), and computed from the pre-prepared standard calibration curve. Each experiment was performed in triplicate under identical conditions and mean values are reported, also reproducible experimental error within $4 \%$ was recorded. The percentage of dye removal biosorption capacity was estimated for each strain as biosorbent material.

\section{Decolorization features of the three isolated strains}

A comparable study was investigated to monitor the effect of decolourization processing conditions for C.I 28 basic yellow dye removal from the simulated synthetic wastewater, using the purified biopolymers extracted from the three innovative Egyptian isolated strains of 40B, 32A, and 38A. The decolourization profile of each strain was determined according to the variation in the physicochemical processing factors, such as contact time (0-60 min), initial dye concentration (5-1000 $\left.\mathrm{mg} \mathrm{L}^{-1}\right)$, weight of extracted purified biopolymer dosage from each strain $(0.01-5 \mathrm{mg})$ (regarding the difficulties in weighing these very small concentrations from purified biopolymers on digital balance, so, solutions of $1 \mathrm{~g} \mathrm{~L}^{-1}$ from each biopolymer prepared as stock and calculated volumes from each stock that belong to the extracted purified biopolymer dosage was withdrawn using micropipette), dye solution $\mathrm{pH}(1-11)$, and dye solution temperature $\left(5-80{ }^{\circ} \mathrm{C}\right)$. The experiments were performed in triplicate to certify that thebiosorption process was caused only by the isolated Egyptian strains.

\section{Equilibrium modelling of the biosorption process}

The adsorption isotherms purpose is to find the suitable relationship between the dye concentration at the solution bulk and the amount of dye adsorbed onto the biosorbent strain when the two phases were at a fixed temperature at equilibrium ${ }^{21}$. The isotherm experimental results were tested using the Langmuir, Freundlich, and Temkin isotherms. The applicability of these isotherm equations to the biosorption systems was compared by judging the correlation coefficients, $R^{2}$. 


\section{Langmuir isotherm}

Langmuir adsorption model suggests that there is a fixed number of well-defined sites available for molecules adsorption that have the ability to hold only one molecule, and there is noadsorbate migration in the plane of material surface. The linear form of the Langmuir isotherm is represented by the following equation ${ }^{22}$ :

$$
\frac{C_{e}}{q_{e}}=\frac{1}{q_{m} K_{L}}+\frac{C_{e}}{q_{m}}
$$

where $q_{e}$ is the amount adsorbed $\left(\mathrm{mg} \mathrm{g}^{-1}\right), C_{e}$ is the adsorbate ions equilibrium concentration $\left(\mathrm{mg} \mathrm{L}^{-1}\right)$, and $q_{m}$ and $K_{L}$ are Langmuir constants correlated to maximum adsorption capacity (monolayer capacity) $\left(\mathrm{mg} \mathrm{g}^{-1}\right)$ and energy of adsorption $\left(\mathrm{L} \mathrm{mg}^{-1}\right)$, respectively.

The essential Langmuir isotherm characteristics are defined by a dimensionless separation factor, $R_{L}$, which is suggestive of the isotherm shape that predicts whether an adsorption system is favourable or unfavourable ${ }^{23} . R_{L}$ is defined as

$$
R_{L}=\frac{1}{1+K_{L} C_{0}}
$$

where $K_{L}$ is the Langmuir constant, and $C_{0}$ is the initial dye concentration.

\section{Freundlich isotherm}

The Freundlich isotherm is an empirical equation for description of the systems heterogeneity and the exponential distribution of sites and their energies. The experimental data have been analysed using the logarithmic form of the Freundlich isotherm as shown below.

$$
\ln q_{e}=\ln K_{F}+\frac{1}{n_{f}} \ln C_{e}
$$

where $K_{F}$ and $n_{f}$ are Freundlich coefficients correlated to capacity and intensity of adsorption, respectively.

\section{Temkin isotherm}

Temkin isotherm supposes that all the molecules in the layer their heat of adsorption was decreased linearly as the action of adsorbent-adsorbate interactions. Moreover, it was assumed uniform distribution of the binding energies at the adsorption process. Temkin model is presented by the following equation ${ }^{24}$.

$$
q_{e}=B \ln K_{T}+B \ln C_{e}
$$

where $B$ is related to the heat of adsorption, and $K_{T}$ is the equilibrium binding constant $\left(\mathrm{L} \mathrm{mg}^{-1}\right)$ corresponding to the maximum binding energy.

\section{Biosorption kinetic models}

Biosorption kinetic studies are important since they not only provide valuable insights into the reaction pathways, but also describe the uptake rate of solute which affects the residence time of sorbate at the solid-liquid interface ${ }^{25}$. In this respect, pseudo first-order, pseudo second-order, Elovich, and intra-particle diffusion kinetic models were examined for C.I basic yellow 28 dye uptake from the simulated synthetic wastewater using Bacillus velezensis (40B) purified biopolymer as the most efficient strain studied.

\section{Pseudo first-order rate model}

The first order rate equation of Lagergren is extensively utilized to describe the sorption of a solute from liquid solution ${ }^{26}$ and is represented as:

$$
\ln \left(q_{e}-q_{t}\right)=\ln q_{e}-k_{1} t
$$

where $q_{e}$ and $q_{t}$ are amounts of dye ions sorbed $\left(\mathrm{mg} \mathrm{g}^{-1}\right)$ at equilibrium and at time $t(\mathrm{~min})$, respectively. $k_{1}\left(\mathrm{~min}^{-1}\right)$ is the first-order reaction rate con$\operatorname{stant}^{27}$.

\section{Pseudo second-order rate model}

Ho's second-order rate distinguishes kinetic equations based on adsorption capacity from concentration of solution. This model depends on sorption equilibrium capacity and can be identified as ${ }^{28}$

$$
t / q_{t}=\left(1 / k_{2} q_{e}^{2}\right)+t / q_{e}
$$

where $k_{2}$ is the second-order reaction rate equilibrium constant $\left(\mathrm{g} \mathrm{mg}^{-1} \mathrm{~min}^{-1}\right)$.

The simple Elovich model

The Elovich model equation is established on the multilayer adsorption, assuming that the adsorption sites increase exponentially with adsorption. It can be written as ${ }^{29}$

$$
q_{t}=\alpha+\beta \ln t
$$

where $\alpha$ represents the rate of chemisorption at zero coverage $\left(\mathrm{mg} \mathrm{g}^{-1} \mathrm{~min}^{-1}\right)$, and $\beta$ is related to the extent of surface coverage and activation energy for chemisorption $\left(\mathrm{g} \mathrm{mg}^{-1}\right)$.

\section{The Intra-particle diffusion model}

Weber-Morris reported that in many adsorption systems, the intra-particle diffusion resistance may affect the sorption process, and the adsorption of solute varies proportionally with $t^{1 / 2}$ rather than with the contact time $t$ according to ${ }^{30}$

$$
q_{t}=k_{\mathrm{id}} t^{1 / 2}+I
$$


where, $k_{\text {id }}$ is the intra-particle diffusion rate constant. Values of $I$ give an idea about the thickness of the boundary layer ${ }^{29}$

\section{Biosorption thermodynamics}

The thermodynamic parameters that must be considered to determine any adsorption process are the changes in standard free energy $\left(\Delta G^{0}\right)$, enthalpy $\left(\Delta H^{0}\right)$, and entropy $\left(\Delta S^{0}\right)$. The value of $\Delta H^{0}$ and $\Delta S^{0}$ can be computed using the Van't Hoff equation ${ }^{31,32}$

$$
\ln K_{c}=\frac{\Delta S^{0}}{R}-\frac{\Delta H^{0}}{R T}
$$

where $R\left(8.314 \mathrm{~J} \mathrm{~mol}^{-1} \mathrm{~K}^{-1}\right)$ is the gas constant, $T$ $(\mathrm{K})$ is the absolute solution temperature in Kelvin, and $K\left(\mathrm{~L} \mathrm{mg}^{-1}\right)$ is the Langmuir isotherm constant. The values of $\Delta H^{0}$ and $\Delta S^{0}$ can be calculated respectively from the slope and intercept of the Van't Hoff plots. After estimation, the values of $\Delta H^{0}$ and $\Delta S^{0}$, $\Delta G^{0}$ can be calculated using the following correlation:

$$
\Delta G^{0}=\Delta H^{0}-T \Delta S^{0}
$$

Table 1 -Composition analysis of purified biopolymers

\begin{tabular}{ccc}
\hline Strain & $\begin{array}{c}\text { Carbohydrates } \\
\text { content }(\% \mathrm{w} .)\end{array}$ & $\begin{array}{c}\text { Protein content } \\
(\% \mathrm{w} .)\end{array}$ \\
\hline Bacillus velezensis (40B) & 98 & 2 \\
Bacillus mojavensis (32A) & 98.4 & 1.6 \\
Pseudomonas (38A) & 94.61 & 2.85 \\
\hline
\end{tabular}

\section{Results and discussion}

\section{Characteristics of the bioflocculants}

The chemical analysis of the purified biopolymers extracted from the cell-free cultures supernatants for the three isolated strains (Bacillus velezensis, Bacillus mojavensis, and Pseudomonas) demonstrates that they contain both protein and polysaccharide. However, their major constituents are shown to be the polysaccharides, as indicated in Table 1. Protein biopolymers are heat-sensitive as protein chains can be destroyed upon heating, how-

\begin{tabular}{|c|c|c|c|c|c|c|c|c|c|c|c|}
\hline \multicolumn{4}{|c|}{ Bacillus velezensis (40B) } & \multicolumn{4}{|c|}{ Bacillus mojavensis (32A) } & \multicolumn{4}{|c|}{ Pseudomonas (38A) } \\
\hline Amino acid & $\begin{array}{l}\text { Content } \\
\%(\mathrm{w} / \mathrm{w})\end{array}$ & Sugar & $\begin{array}{l}\text { Content } \\
\%(\mathrm{w} / \mathrm{w})\end{array}$ & Amino acid & $\begin{array}{c}\text { Content } \\
\%(\mathrm{w} / \mathrm{w})\end{array}$ & Sugar & $\begin{array}{l}\text { Content } \\
\%(\mathrm{w} / \mathrm{w})\end{array}$ & Amino acid & $\begin{array}{l}\text { Content } \\
\%(\mathrm{w} / \mathrm{w})\end{array}$ & Sugar & $\begin{array}{l}\text { Content } \\
\%(\mathrm{w} / \mathrm{w})\end{array}$ \\
\hline Aspartic acid & 7.91 & Xylose & 4.21 & Aspartic acid & 9.82 & Xylose & 7.82 & $\begin{array}{l}\text { Aspartic } \\
\text { acid }\end{array}$ & 6.52 & Xylose & 6.38 \\
\hline Threonine & 2.91 & Glucose & 90.7 & Threonine & 2.32 & Fructose & 10.63 & Threonine & 1.67 & Fructose & 4.36 \\
\hline Serine & 1.69 & Sucrose & 2.74 & Serine & 2.19 & Sucrose & 28.7 & Serine & 1.61 & Glucose & 95.47 \\
\hline Glutamic acid & 40.34 & Lactose & 2.34 & Glutamic acid & 38.28 & Maltose & 29.85 & $\begin{array}{l}\text { Glutamic } \\
\text { acid }\end{array}$ & 59.58 & Sucrose & 35.97 \\
\hline Proline & 3.42 & & & Proline & 1.81 & Lactose & 22.97 & Proline & 1.61 & Maltose & 30.07 \\
\hline Glycine & 6.62 & & & Glycine & 8.06 & & & Glycine & 4.94 & Lactose & 23.91 \\
\hline Alanine & 5.46 & & & Alanine & 5.40 & & & Alanine & 3.39 & Lactulose & 24.76 \\
\hline Valine & 5.46 & & & Valine & 4.99 & & & Valine & 2.54 & & \\
\hline Methionine & 2.86 & & & Methionine & 1.60 & & & Methionine & 0.80 & & \\
\hline Isoleucine & 3.52 & & & Isoleucine & 4.23 & & & Isoleucine & 2.81 & & \\
\hline Leucine & 4.51 & & & Leucine & 5.35 & & & Leucine & 3.35 & & \\
\hline Tyrosine & 0.04 & & & Tyrosine & 1.94 & & & Tyrosine & 0.60 & & \\
\hline Phenylalanine & 2.71 & & & Phenylalanine & 2.34 & & & Phenylalanine & ne 1.83 & & \\
\hline Histidine & 5.67 & & & Histidine & 3.02 & & & Histidine & 3.01 & & \\
\hline Lysine & 4.39 & & & Lysine & 5.33 & & & Lysine & 3.60 & & \\
\hline Ammonia & 0.45 & & & Ammonia & 0.46 & & & & & & \\
\hline Arginine & 1.97 & & & Arginine & 2.76 & & & & & & \\
\hline
\end{tabular}

Table 2 - Amino acid and sugar composition of purified biopolymers 
ever, polysaccharide biopolymers exhibit high heat-resistance properties.

According to Table 1, the isolated biopolymers are mainly polysaccharides. Thus, they are characterized by their thermal stabilities above high temperature range $\mathrm{e}^{15-17}$. Regarding these results, the extracted biopolymers may be of great importance in industrial wastewater treatment applications. The amino acids compositions of the three purified biopolymers were determined after acid hydrolysis. As stated in Table 2, the three biopolymers were rich in glutamic acid, aspartic acid and glycine, respectively. However, HPLC analysis reveals that mono-sugar glucose is the major sugar component of the two biopolymers extracted from 40B and 38A. Furthermore, it was evident that the main sugars of the biopolymer that was extracted from $32 \mathrm{~A}$ were sucrose, maltose and lactose.

In order to determine the main functional groups present at each extracted biopolymer responsible for the basic dye flocculation, the FTIR spectrum of the three purified biopolymers was analysed. The infrared spectrum of the analysed biopolymers (Figure 1) confirms the presence of carboxyl, hydroxyl, amino, and methoxyl groups in all the three bioflocculants. These results are in agreement with previous chemical analysis data of biopolymers, which are mainly composed of polysaccharide and protein. These three main functional groups present in each bioflocculant were identified by the broad stretching intense peak around 3430 $\mathrm{cm}^{-1}$ that is characteristic for hydroxyl and amino groups. In addition, the bands around $1620 \mathrm{~cm}^{-1}$ and $1410 \mathrm{~cm}^{-1}$ could be assigned to the $\mathrm{C}=\mathrm{O}$ anti-symmetrical and symmetrical stretching in the carboxylate, respectively ${ }^{13}$. Furthermore, the peak shown around $1075 \mathrm{~cm}^{-1}$ isgenerally known to be a typical characteristic of all sugar derivatives. Presence of carboxyl and hydroxyl groups inside the biopolymers structure improves their adsorptive forces, which increases the dye sorption onto the bioflocculant. Consequently, these main functional groups in each polymer may be the responsible groups for the dye bioflocculation process.

\section{Decolourization behaviours of the biopolymers toward real and synthetic simulated wastewater purification}

The decolourization efficiency of the three $40 \mathrm{~B}, 32 \mathrm{~A}$, and $38 \mathrm{~A}$ purified biopolymers toward basic yellow 28 from both real discharged polluted wastewater from AKSA EGYPT acrylic fibres industry and the simulated polluted wastewater was compared and investigated. The evolution of colour removal from the real wastewater declined to its half value compared with the colour evolution from the simulated wastewater for the three studied

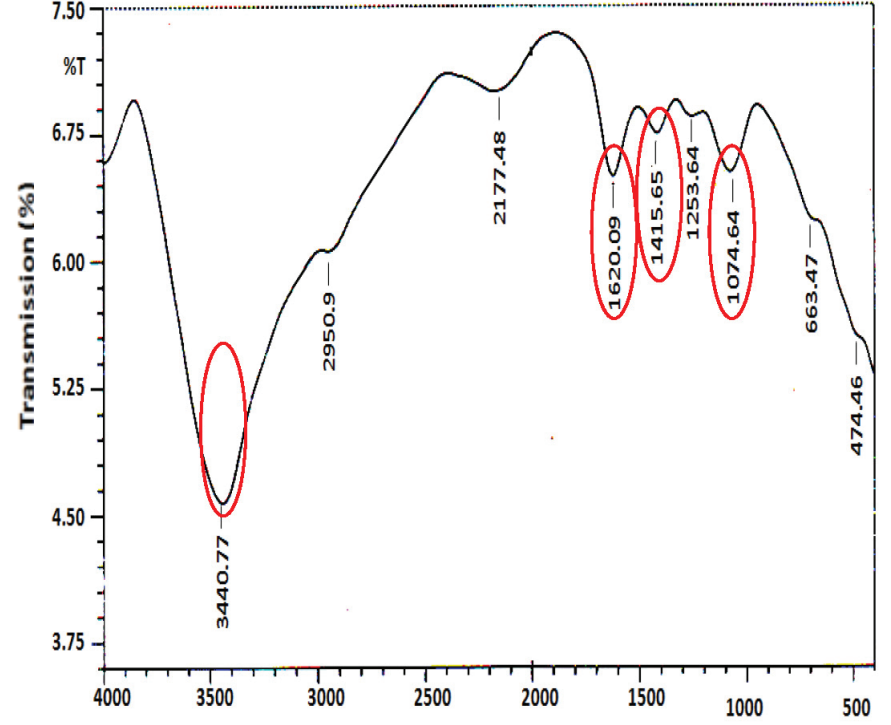

a)

Wavelength, $\mathrm{cm}^{-1}$
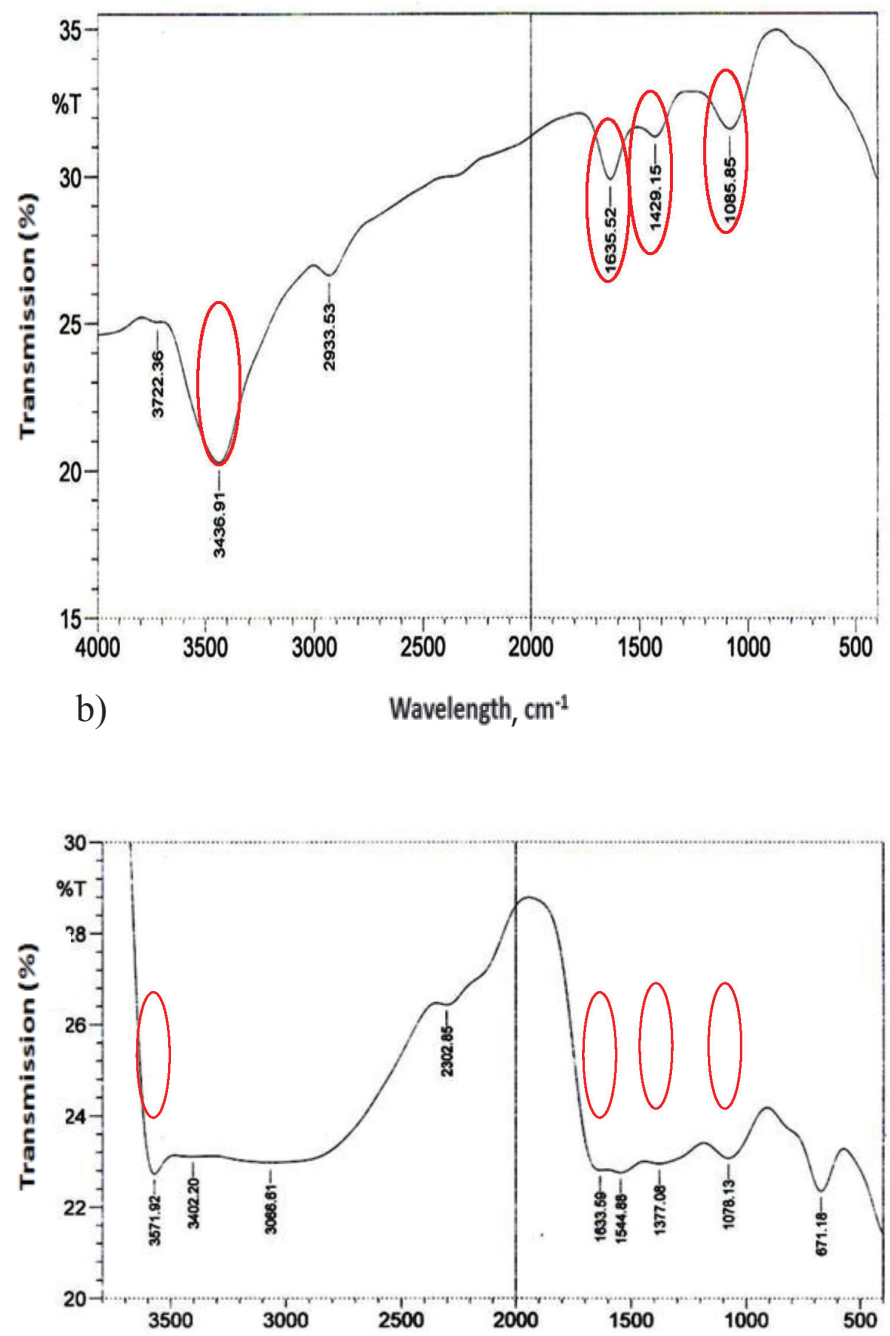

c)

Wavelength, $\mathrm{cm}^{-1}$

Fig. 1-FTIR analysis of the three purified biopolymers a) Bacillus velezensis, b)Bacillus mojavensis, and c) Pseudomonas 


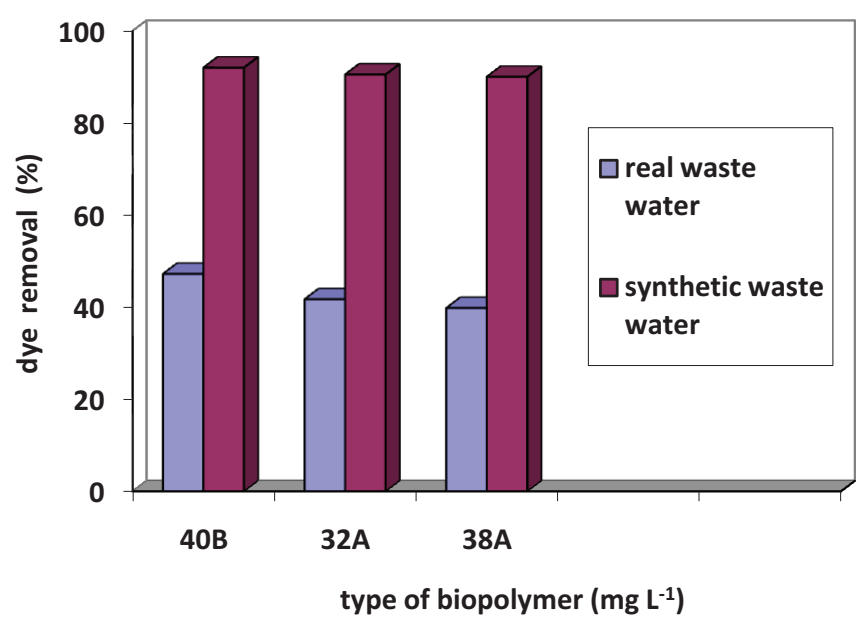

Fig. 2 - Decolourization behaviour of three biopolymers in real and synthetic wastewater

strains, as shown in Figure 2. This reduction in the decolourization efficiency of the biopolymer for real wastewater decolourization could be due to the presence of suspended solids inthe real discharged wastewater rather than the synthetic one. The presence of suspended solids was confirmed by measuring the turbidity value of the real wastewater, which was 11.8 NTU compared with 0.0 NTU for the synthetic wastewater. As these three isolated biopolymers (40B, 32A, and 38A) were previously confirmed as efficient bioflocculants for suspended solids $^{15-17}$, the reactivity of the utilized biopolymer for real wastewater decolourization may be partially consumed in the bioflocculation process of the suspended solids. On the other hand, the hydrogen ion concentration of the real discharged wastewater that is measured as 2.7 is comparatively higher than that of the synthetic wastewater (neutral $\mathrm{pH}=7$ ). This acidic characteristic of the real wastewater indicates presence of hydrogen ions $\left(\mathrm{H}^{+}\right)$that compete with the cationic ions of dye and decrease the biopolymer efficiency for decolourization process ${ }^{33}$. Therefore, in order to elucidate the accurate biosorption properties of the three 40B, 32A, and 38A biopolymers toward basic yellow 28 dye decolourization, further studies will be conducted using simulated wastewater that includes specific dye pollutant. That is in order to eliminate any interference effect of other contaminants present in the real dye polluted wastewater

\section{Effect of adsorption parameters}

\section{Effect of dye solution $\mathrm{pH}$}

The acidity degree of wastewater polluted with dye is one of the primary parameters controlling the sorption process due to its impact on both the surface binding sites of the biosorbent and the ioniza- tion process of the dye molecule ${ }^{34}$. Change in $\mathrm{pH}$ affects the adsorptive process through dissociation of functional groups on the biosorbent surface active sites. Where both hydrogen and hydroxyl ions were adsorbed quite strongly, the other ions adsorption is influenced by the solution's $\mathrm{pH}$. This by its role tends to shift the kinetics and equilibrium of the biosorption process ${ }^{35}$. In the current biosorption systems, after 30 min-equilibration with the different biopolymers, the percentage of dye removal increases with increasing the $\mathrm{pH}$ value up to 7 , then tend to deplete as the $\mathrm{pH}$ value rises above 7 (Figure not presented). This may be attributed to the presence of hydrogen ions $\left(\mathrm{H}^{+}\right)$at lower $\mathrm{pH}$ (acidic dye solution) that compete with dye molecules and reduce the quantity of the adsorbed basic yellow dye by the biopolymers ${ }^{36}$. However, as the $\mathrm{pH}$ value of the dye solution approaches 7, the biopolymers surfaces become negatively charged (Figure 3 ) due to the ionization of functional groups, such as hydroxyl and carboxyl groups present in the three biosorbents, which enhances the sorption of the positively charged dye cations through electrostatic forces of attraction ${ }^{34}$. The maximum adsorption of the dye onto the three biopolymers is recorded at $\mathrm{pH}$ range of 5-7. This data is in agreement with the previous results that stated the $\mathrm{pH}$ stabilities of the three biopolymer solution are recorded at $\mathrm{pH}$ range of 3-9 and they reach their maximum stabilities at $\mathrm{pH}$ value of $7^{15-17}$. As the effective $\mathrm{pH}$ value was 7 , this value was used to complete the study. This biosorption feature of the three studied biopolymers (40B, 32A, and 38A) varies unlike those obtained from dried Cephalosporiuma phidicola cells ${ }^{37}$ and acid-treated biomass of brown seaweed Laminaria sp. ${ }^{48}$, but in agreement with those gained from $\mathrm{Aza}$ dirachta indica leaf powder and Posidonia oceanica (L.) fibres ${ }^{34}$.

\section{Effect of initial dye concentration and contact time}

The biosorption of the basic yellow dye onto the purified three biopolymers as function of contact time at different initial dye concentrations has been investigated. The biosorption of BY28 dye onto the biopolymers was rapid at any initial dye concentration in the first $10 \mathrm{~min}$, then attained equilibrium within $30 \mathrm{~min}$ (Figure not presented). All studied biopolymers exhibited slow and quantitatively insignificant dye removal after $30 \mathrm{~min}$. Therefore, the biosorption rate was speculated to deteriorate with time due to the continuous decrease in the dye concentration driving force.

Moreover, for all studied strains, the percentage of dye uptake shows a declining trend as the initial concentration of the dye increased. However, the biopolymer's dye removal capacity increased with increasing the initial dye concentrations, as 


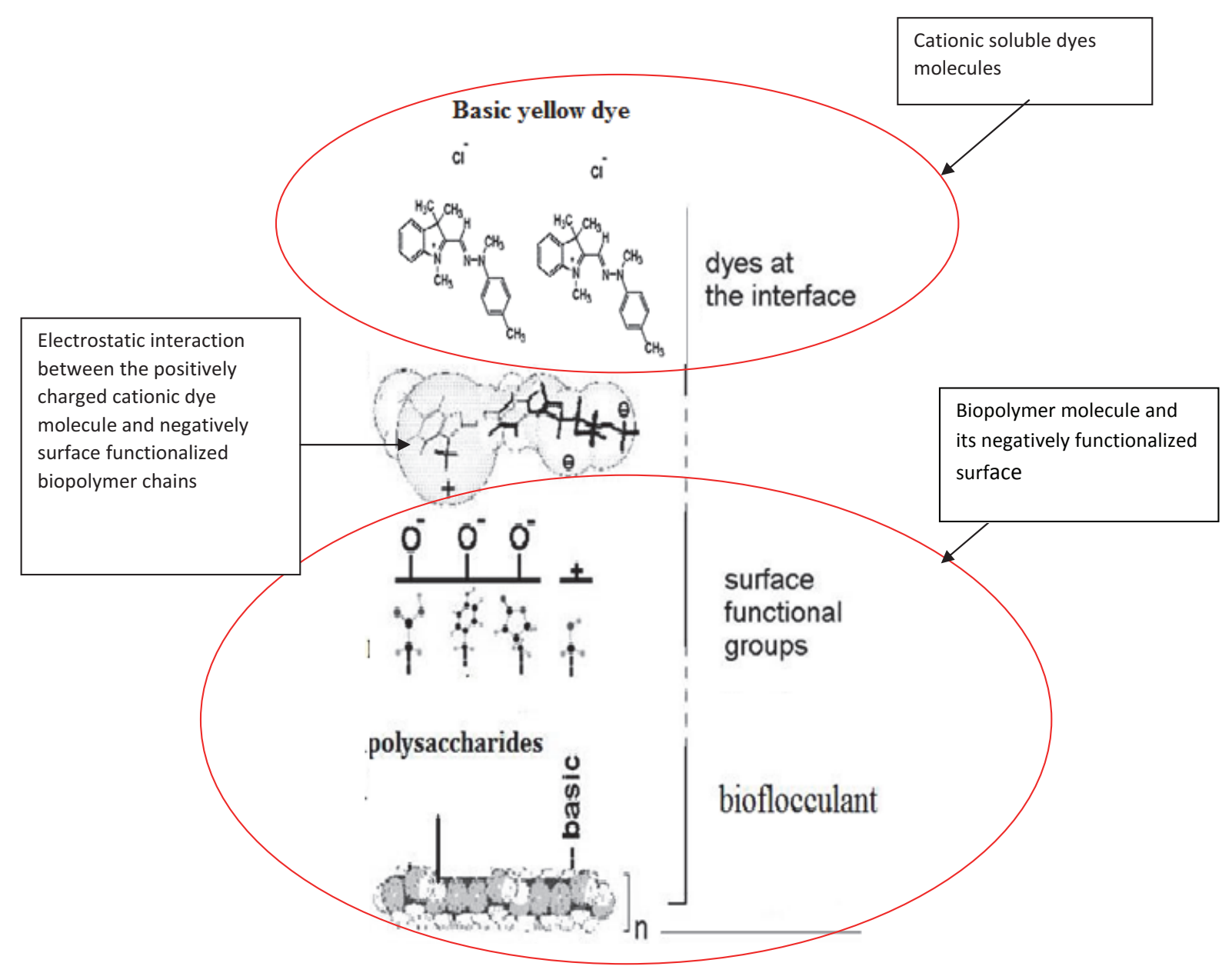

Fig. 3 - Model depicting the interaction between cationic dye molecules and biopolymer surface

shown in Figure 4. These results were in harmony with previous findings ${ }^{39,40}$. It can be attributed to the reduction in available active sites on the biopolymers for dye removal when the dye concentration increases. Besides, the increase of dye molecules adsorbed onto the external surface of the biopolymers, increases significantly the local dye concentration, giving rise to the formation of aggregates of the dye on the biopolymer molecules that obstruct the diffusion of dye molecules into the intra-particle matrix $^{32}$. On the other hand, the increment in the amount of the dye adsorbed onto the biopolymers with an increase in the initial dye concentration using constant biopolymer amount is attributed to the enhancement ofthe concentration gradient driving force at high initial dye concentrations. At low initial dye concentrations, the dye sorption by the three biopolymers was fast and the equilibrium was recorded quickly. This gives a prediction about the probability of monolayer coverage formation of dye molecules at the surface of the three biopolymers. At fixed biopolymer dosage, the dye molecules residual concentration will increase with increasing initial dye concentrations. At low dye concentra- tions, the number fraction of initial dye molecules to the available adsorption sites is low. At higher concentrations, the number of available biopolymer sorption sites becomes lower, and subsequently the removal of dyes depends on the initial concentration. At high concentrations, it is unlikely that dyes are only adsorbed in a monolayer at the outer interface of the three biosorbents ${ }^{41}$.

\section{Effect of biopolymers dosage}

Adsorbent dosage is an essential factor to determine the adsorbent capacity for fixed adsorbate initial concentration. The effect of biosorbent dosage $(40 \mathrm{~B}, 32 \mathrm{~A}, 38 \mathrm{~A})$ was studied on BY28 dye removal, keeping all other conditions constant (Figure 5). The results show that, for all three studied biopolymers, as the biopolymer concentration increased, the percentage of adsorption generally increased, but the amount adsorbed per unit mass of the adsorbent decreased considerably. Accordingly, the sorption capacity of the studied biopolymers was found to be high at low dosages. This behaviour may be explained by improvement in the adsorbent 


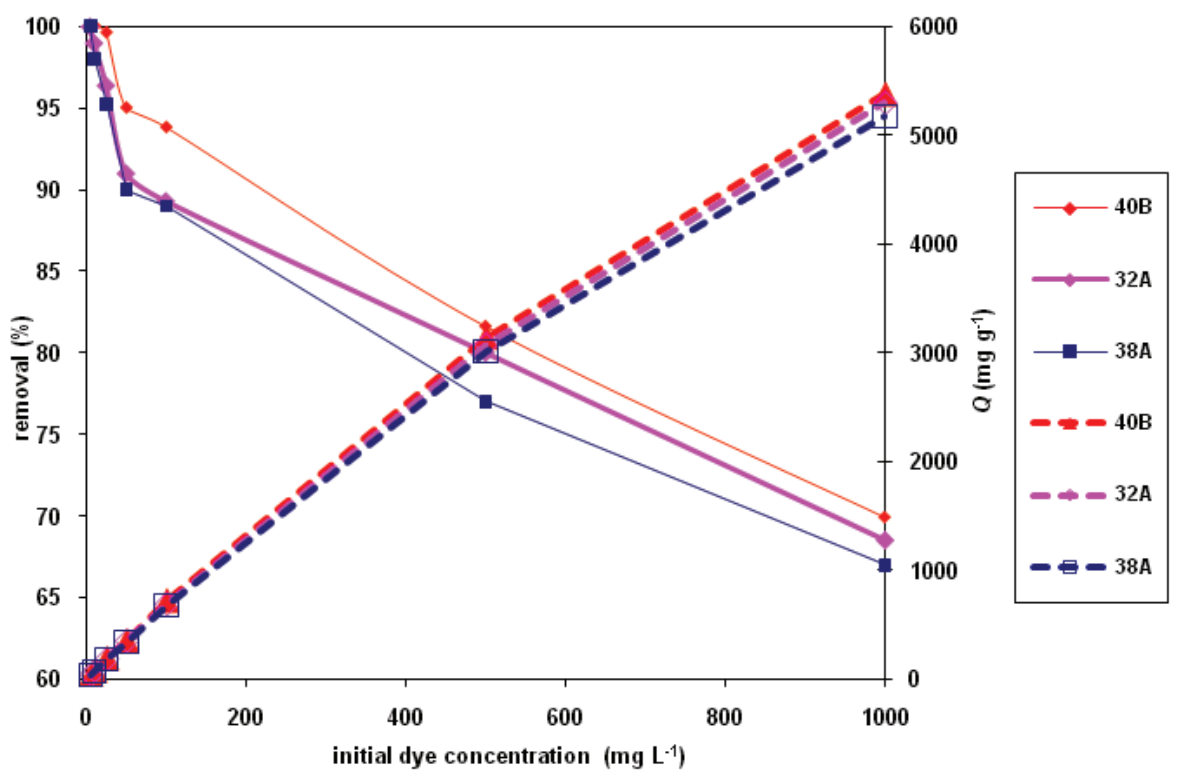

Fig. 4 - Effect of initial dye concentration on both the dye removal percentage and capacity using three biopolymers

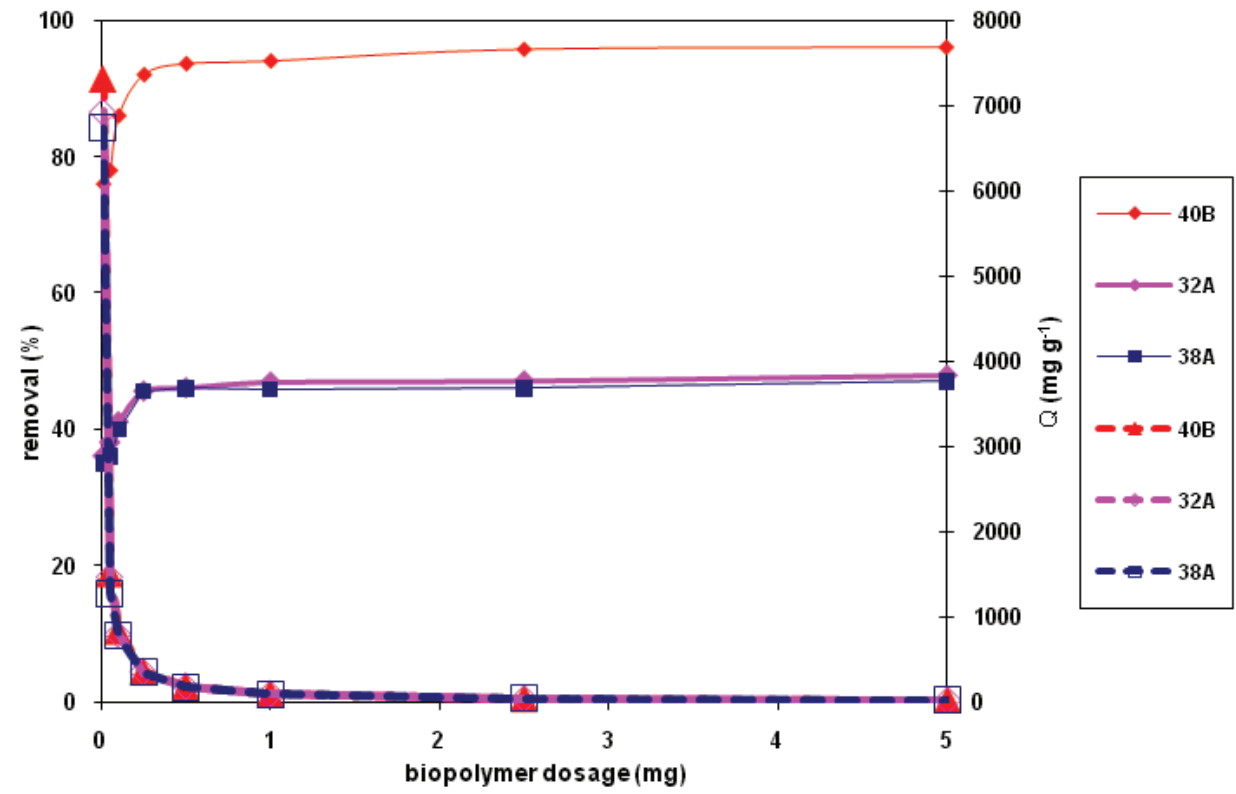

Fig. 5 - Effect of biopolymer dosage on both the dye removal percentage and capacity using the three extracted biopolymers

surface with increment in the biopolymer dosage and the availability of more adsorption sites for dye removal. However, for fixed dye concentrations, as the biopolymer dosage increased, the remaining available unsaturated adsorption sites onto the biopolymers increased during the adsorption reaction, which decreased the biopolymer capacity.

Additionally, as the biopolymer dosage increase above limited range (optimum dosage), biopolymer adsorption sites might overlap or aggregate, which decreases the available total adsorbent surface area for dye molecules and increases the diffusion path length ${ }^{42}$. Comparison of the dye removal capacities of the three studied biopolymers at the different studied dosages indicated that 40B biopolymer had the maximum dye capacity; however, 38A biopolymer showed the minimum dye removal capacity at the different studied biopolymers dosages. In order to compare the decolourization performance of our three Egyptian isolated strains with literature, Table 3 explores a comparative investigation of dye decolourization efficiencies of our three Egyptian isolated strains with those recorded in the literature for the other studied strains utilized for 
Table 3 -Comparison of dye decolourization performance of three isolated strains with other literature strains

\begin{tabular}{|c|c|c|c|c|}
\hline Isolated bacterial strain & Dye type & $\begin{array}{l}\text { Dye adsorption } \\
\text { capacity }\left(\mathrm{mg} \mathrm{g}^{-1}\right)\end{array}$ & Decolourization parameters & Reference \\
\hline Bacillus velezensis (40B) & C.I 28 basic yellow dye & 90.8 & $\begin{array}{c}\text { Time }=30 \mathrm{~min}, \text { dosage }=1 \mathrm{mg} \mathrm{L}^{-1}, \\
\mathrm{pH}=7 \text { and } T=25^{\circ} \mathrm{C}\end{array}$ & Present work \\
\hline Bacillus mojavensis (32A) & C.I 28 basic yellow dye & 90 & $\begin{array}{c}\text { Time }=30 \mathrm{~min} \text {, dosage }=1 \mathrm{mg} \mathrm{L}^{-1} \\
\mathrm{pH}=7 \text { and } T=25^{\circ} \mathrm{C}\end{array}$ & Present work \\
\hline Pseudomonas (38A) & C.I 28 basic yellow dye & 89.2 & $\begin{array}{c}\text { Time }=30 \mathrm{~min}, \text { dosage }=1 \mathrm{mg} \mathrm{L}^{-1} \\
\mathrm{pH}=7 \text { and } T=25^{\circ} \mathrm{C}\end{array}$ & Present work \\
\hline Staphylococcus sp. (ES-37) & Remazol golden yellow & 42.7 & $\begin{array}{c}\text { Time }=30 \mathrm{~min}, \text { dosage }=1 \mathrm{mg} \mathrm{L}^{-1} \\
\mathrm{pH}=7 \text { and } T=25^{\circ} \mathrm{C}\end{array}$ & Palanivelan et al. ${ }^{43}$ \\
\hline Bacillus sp. (ESL-52) & Remazol golden yellow & 66.2 & $\begin{array}{c}\text { Time }=12 \text { days, dosage }=1 \mathrm{mg} \mathrm{L}^{-1} \text {, } \\
\mathrm{pH}=7 \text { and } T=25{ }^{\circ} \mathrm{C}\end{array}$ & Palanivelan et al. $^{43}$ \\
\hline Bacillus sp. (TSL-9) & Remazol golden yellow & 40.1 & $\begin{array}{c}\text { Time }=12 \text { days, dosage }=1 \mathrm{mg} \mathrm{L}^{-1} \text {, } \\
\mathrm{pH}=7 \text { and } T=25^{\circ} \mathrm{C}\end{array}$ & Palanivelan et al..$^{43}$ \\
\hline Micrococcus sp. (TSL-7) & Remazol golden yellow & 52.6 & $\begin{array}{c}\text { Time }=12 \text { days, dosage }=1 \mathrm{mg} \mathrm{L}^{-1}, \\
\mathrm{pH}=7 \text { and } T=25^{\circ} \mathrm{C}\end{array}$ & Palanivelan et al. ${ }^{43}$ \\
\hline Lactobacillus sp. (TS-5) & Remazol golden yellow & 33.8 & $\begin{array}{c}\text { Time }=12 \text { days, dosage }=1 \mathrm{mg} \mathrm{L}^{-1}, \\
\mathrm{pH}=7 \text { and } T=25^{\circ} \mathrm{C}\end{array}$ & Palanivelan et al..$^{43}$ \\
\hline Pseudomonas sp. (M-1) & Remazol golden yellow & 63.54 & $\begin{array}{c}\text { Time }=12 \text { days, dosage }=1 \mathrm{mg} \mathrm{L}^{-1} \text {, } \\
\mathrm{pH}=7 \text { and } T=25^{\circ} \mathrm{C}\end{array}$ & Palanivelan et al..$^{43}$ \\
\hline
\end{tabular}

Table 4 -Estimated equilibrium parameters of the three studied equilibrium isotherms for dye adsorption onto the three isolated biopolymers

\begin{tabular}{c|c|c|c|c|c|c|c|c|c|c}
\hline $\begin{array}{c}\text { Equilibrium } \\
\text { isotherm }\end{array}$ & \multicolumn{3}{c}{ Langmuir constant } & \multicolumn{3}{c|}{ Freundlich constant } & \multicolumn{5}{c}{ Temkin constant } \\
\hline biopolymer & $q_{m}\left(\mathrm{mg} \mathrm{g}^{-1}\right)$ & $K_{L}\left(\mathrm{~L} \mathrm{mg}^{-1}\right)$ & $R^{2}$ & $R_{L}$ & $K_{F}\left(\mathrm{mg} \mathrm{g}^{-1}\right)$ & $n_{F}$ & $R^{2}$ & $K_{T}\left(\mathrm{~L} \mathrm{mg}^{-1}\right)$ & $B_{1}$ & $R^{2}$ \\
\hline 40B & 23.8 & 0.0182 & 0.983 & 0.524 & 1.28 & 2.285 & 0.923 & 957.98 & 1.21 & 0.967 \\
32A & 20.2 & 0.017 & 0.988 & 0.582 & 1.271 & 2.2548 & 0.944 & 709.95 & 1.187 & 0.971 \\
$38 \mathrm{~A}$ & 18.4 & 0.0163 & 0.9818 & 0.544 & 1.273 & 2.248 & 0.941 & 625.3 & 1.152 & 0.972 \\
\hline
\end{tabular}

dye decolourization. It is evident, from the table, that our three isolated strains $(40 \mathrm{~B}, 32 \mathrm{~A}, 38 \mathrm{~A})$ have a comparatively high percentage of decolourization compared with the other bacterial strains ${ }^{43}$. Moreover, the time recorded for our isolated strains to accomplish the decolourization process with high efficiency is very short compared with that required for the other literature comparative strains. Consequently, the purified biopolymers of the three Egyptian isolated strains $(40 \mathrm{~B}, 32 \mathrm{~A}, 38 \mathrm{~A})$ represent cost-effective and time-saving matrices for dye decolourization process compared with other isolated bioflocculants.

\section{Equilibrium modelling for the biosorption process}

Equilibrium adsorption isotherm is a graphical representation indicating the relation between the mass of dye adsorbed at fixed temperature and equilibrium.
Adsorption isotherms provide information on how adsorption system progress, and indicate how efficiently a given adsorbent interacts with adsorbate $^{44}$. Figure 6 investigates the experimental data fitting using three isotherm equations, namely, Langmuir, Freundlich, and Temkin for BY28 dye biosorption using the three isolated strains. The applicability of these models is compared by correlation coefficients values, $R^{2}$ given in Table 4. Apparently, both Langmuir and Temkin isotherm models (Figure 6a,c) present the best adjustment for dye removal by each biopolymer with high correlation coefficient $\left(R^{2} \geq 0.96\right)$ over the whole concentration range studied. Nevertheless, Freundlich (Figure 6b) does not give very good adjustments associated with low values from correlation coefficient. The applicability of the Langmuir model recommends that the dye adsorption mainly depends upon monolayer adsorption of each dye molecule with the similar activation energy. This observation suggests 

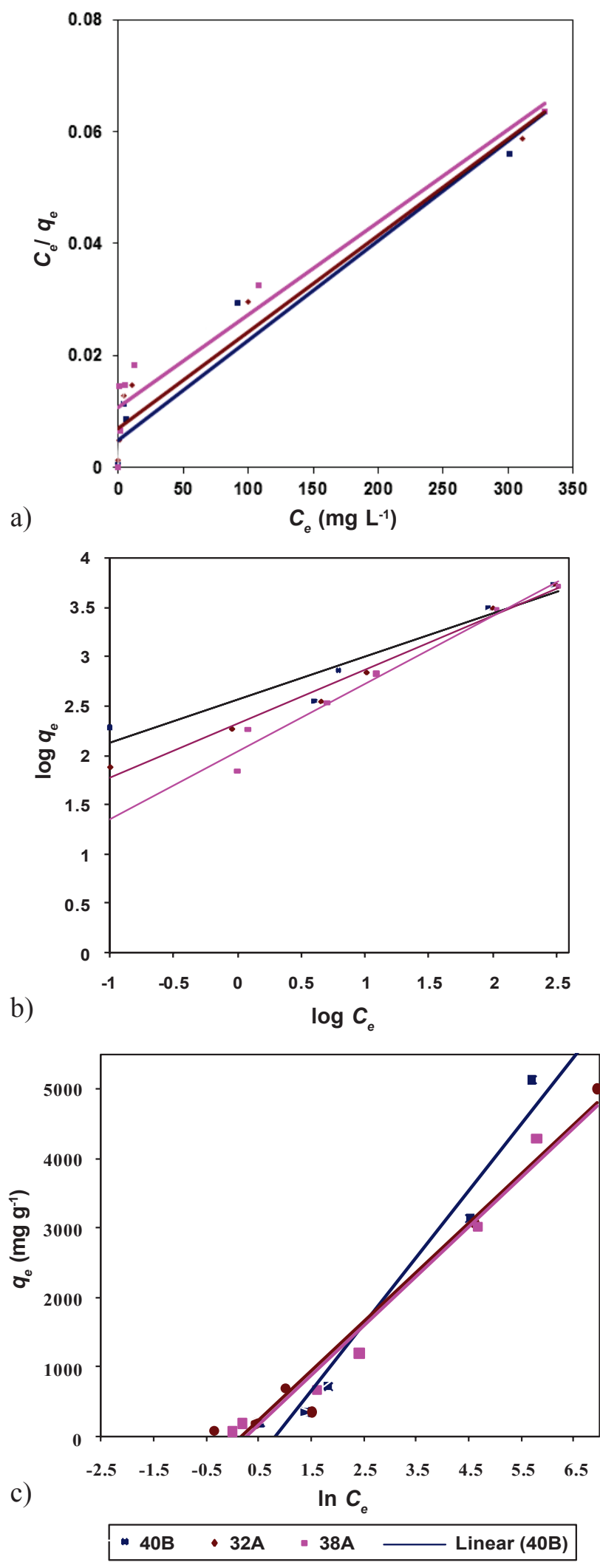

Fig. 6 - Equilibrium isotherms for dye removal using the three different isolated biopolymers (a) Langmuir, (b) Freundlich, (c) Temkin

that the uptake of dyes by the three isolated biopolymers is associated with chemical forces rather than physical interaction ${ }^{45}$. The derived unknown parameters of each applied isotherm model that fitted well with the experimental data are reported in Table 4. Furthermore, the calculated values of dimensionless constant separation factor or equilibrium parameter $R_{L}$, which represent the main characteristics of the Langmuir isotherm, are listed in the same table. Comparing the sorption parameters of the three different biopolymers for dye removal detectable from Langmuir isotherm, the same observations as previously stated can be made, that the 40B biopolymer records the largest monolayer capacity for dye removal that equals $32.8 \mathrm{mg} \mathrm{g}^{-1}$. The biopolymer $38 \mathrm{~A}$ records the lowest monolayer capacity for dye removal that equals $18.4 \mathrm{mg} \mathrm{g}^{-1}$. Furthermore, the calculated values of the Langmuir important feature expressed by separation factor $\left(R_{L}\right)$ show favourable adsorption of the basic dye onto all studied biopolymers, since the $R_{L}$ values fall between zero and one, as given in Table 4. This data confirms that the Langmuir isotherm was favourable for BY28 dye adsorption onto the three biopolymers. On the other hand, the Temkin equation is applicable to authorize that the dye adsorption process is considered by a uniform distribution of the binding energies ${ }^{46}$. On the basis of Temkin constants (Table 4) that are corresponding to the maximum binding energy and the heat of adsorption, the maximum dye binding value of $957.98 \mathrm{~L} \mathrm{~g}^{-1}$ was recorded for the 40B biopolymer, rather than the minimum one of $625.3 \mathrm{~L} \mathrm{~g}^{-1}$ recorded for 38A biopolymer. Accordingly, 40B biopolymer proved to be the best isolated biopolymer for BY28 dye adsorption.

\section{Influence of thermal behaviour and biosorption thermodynamics}

Temperature is the key parameter that affects the rate of adsorption kinetics, uptake and diffusion process. Biosorption dynamics of BY28 dye was conducted at six different temperatures $(5,25,45$, 55,65 and $80{ }^{\circ} \mathrm{C}$ ). Results show a decrease in the amount of dye adsorbed by the three studied biopolymers (40B, 32A, 38A) following the increase intemperature (Figure not shown). This pattern is mainly due to the decrease in biopolymers surface activity suggesting that the dye biosorption onto the three biopolymers is an exothermic process ${ }^{47}$. Accordingly, the increase in temperature decreases the physical forces responsible for sorption. Furthermore, the decrease in the percentage of dye removal at higher temperatures (above $60{ }^{\circ} \mathrm{C}$ ) may be attributed to the biopolymers degradation. Where the main backbone of these biopolymers is polysaccharides, at elevated temperatures, these chains tend to degrade, which reduces the biopolymers efficiencies for dye removal ${ }^{15-17}$. Considering all studied biosorption processing conditions, it is demonstrat- 
Table 5 - Thermodynamic parameters of dye adsorption onto the isolated $40 B$ biopolymer

\begin{tabular}{c|c|c|c|c|c|c|c|c}
\hline \multirow{2}{*}{$\begin{array}{c}\text { Dye } \\
\text { concentration } \\
\left(\mathrm{mg} \mathrm{L}^{-1}\right)\end{array}$} & $\begin{array}{c}\Delta H \\
\left(\mathrm{~kJ} \mathrm{~mol}^{-1}\right)\end{array}$ & $\begin{array}{c}\Delta S \\
\left(\mathrm{~J} \mathrm{~mol}^{-1} \mathrm{~K}^{-1}\right)\end{array}$ & \multicolumn{7}{|c}{$\Delta G\left(\mathrm{~kJ} \mathrm{~mol}^{-1}\right)$} & \multicolumn{5}{c}{} \\
\cline { 4 - 10 } & & & $278 \mathrm{~K}$ & $298 \mathrm{~K}$ & $318 \mathrm{~K}$ & $328 \mathrm{~K}$ & $338 \mathrm{~K}$ & $353 \mathrm{~K}$ \\
\hline 25 & -867.5 & -2.43 & -191.9 & -143.36 & -94.76 & -70.96 & -46.16 & -9.71 \\
50 & -117.66 & -0.23 & -53.72 & -49.12 & -44.52 & -42.12 & -39.92 & -3.64 \\
100 & -84.74 & -0.13 & -7 & -46 & -43.4 & -42.1 & -40.8 & -3.88 \\
500 & -26.3 & -0.07 & -6.84 & -5.44 & -4.04 & -3.34 & -2.64 & -1.59 \\
1000 & -9.1 & -0.023 & -2.7 & -2.25 & -1.786 & -1.56 & -1.326 & -0.981 \\
\hline
\end{tabular}

ed that the three isolated strains are almost identical in their behaviour against the BY28 dye removal. However, Bacillus velezensis (40B) strain proved to be the most efficient biopolymer for BY28 dye uptake compared with the other two strains. Accordingly, the kinetics and thermodynamics of the dye biosorption process were investigated using 40B biopolymer.

Thermodynamic parameters including change in the Gibbs free energy, enthalpy, and entropy are the definite indicators for the application of basic yellow dye adsorption process onto biopolymer 40B. According to the values of these parameters, the spontaneous process can be determined. The linear plot of the Van't Hoff equation at the different studied dye concentrations over the studied temperature range is established and shown in Figure 7.

The plots are used to compute the values of thermodynamic parameters (Table 5). The values of enthalpy change $\left(\Delta H^{0}\right)$ and the entropy change $\left(\Delta S^{0}\right)$ recorded from this work are presented in Table 5. It was found that the Gibbs free energy $\Delta G^{0}$ values decreased with increasing temperature for all studied dye concentrations, demonstrating that the adsorption process tends to decrease the Gibbs energy. The

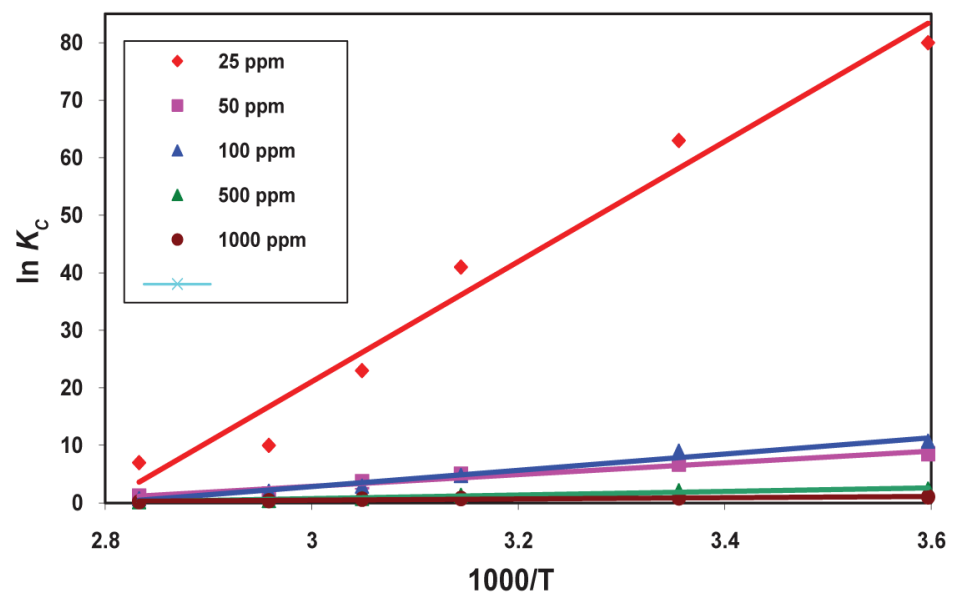

Fig. 7 - Van't Hoff plot for removal of different initial dye concentrations using isolated $40 B$ biopolymer at different solution temperatures negative value of free energy change indicated the spontaneous nature of dye sorption and confirmed affinity of 40B biopolymer sorbent for the dyes ${ }^{48}$. Moreover, the negative $\Delta H^{0}$ value suggests the exothermic nature of adsorption ${ }^{48}$. This suggestion is compatible with the earlier results that explain the effect of dye solution temperature on the biosorption process. While the negative values of $\Delta S^{0}$ can be used to describe the randomness at the $40 \mathrm{~B}$ biopolymer-solution interface during the biosorption process, the thermodynamic parameters indicate that this adsorption process can be used for the removal of basic yellow dye ions by the isolated biopolymer.

\section{Kinetic modelling for the biosorption process}

Various kinetic models, namely pseudo first-order, pseudo second-order, Elovich models, and intra-particle diffusion, have been tested for their validity with the experimental adsorption data for basic yellow dye sorption onto the most efficient extracted biopolymer (40B). In order to find the order of dye kinetic sorption, Lagergren equation was first tested but the straight lines could not linearize well (Figure 8).

As for the Lagergren plots, correlation coefficients were below 0.95 and the calculated qe were not equal to experimental $q_{e}$, signifying the inadequacy of the model to represent the kinetic data for the initial dye concentrations examined. However, the suitability of the pseudo second-order model suggested by Ho and McKay is explored and shown in Figure 8. The plot of $t / q_{t}$ versus $t$ gives a linear relationship, which allows computation of $k_{2}$ and $q_{e}$ without knowing any parameter beforehand ${ }^{48}$. These parameters were recorded from the linear regression, which are reported in Table 6. The results show that the adsorption system followed the Ho and McKay equations for the entire adsorption period, with regression coefficients higher than 0.998 for the dye concentration range used in this study.

The calculated $q_{e}$ values from the model are in agreement with the experimental values as well. Kinetics of basic dye adsorption on the extracted bio- 


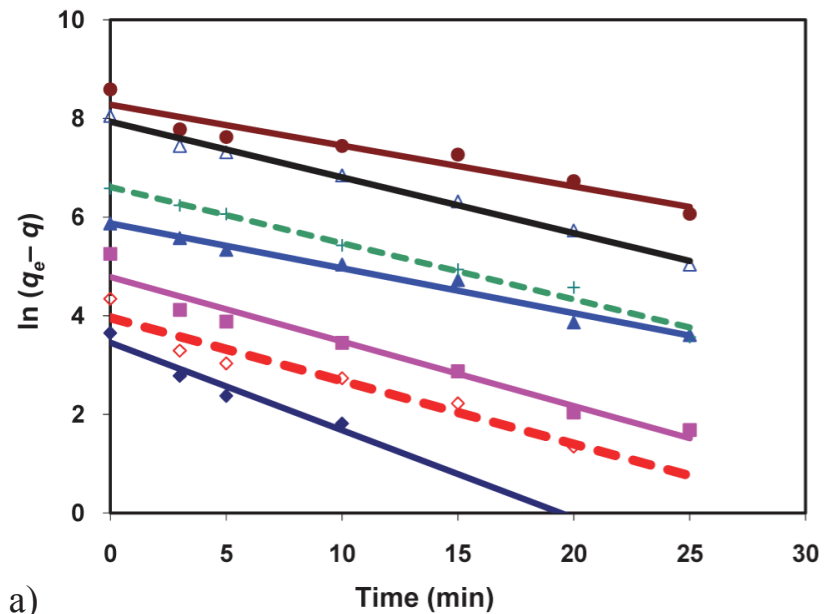

a) Time (min)

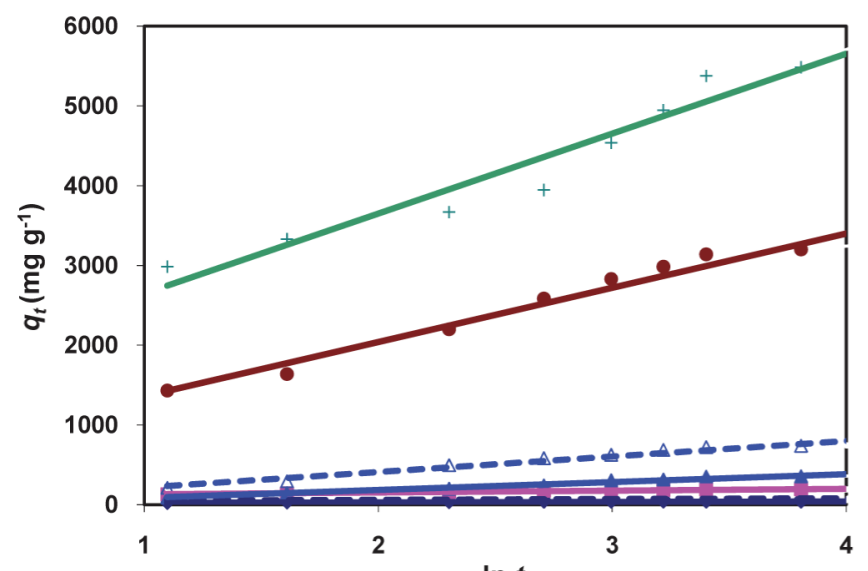

c)

In $t$

Fig. 8 - Kinetic models for decolourization of different dye concentrations using $40 B$ isolated biopolymer (a) pseudo first-order, (b) pseudo second-order, (c) Elovich, (d) intra-particle diffusion

polymer followed the pseudo second-order model, suggesting that the rate-limiting step may be chemisorption ${ }^{49}$. This confirms that the dye adsorption process may have occurred through surface exchange mechanisms until occupying the surface functional sites onto the biopolymer. Subsequently, the dye molecules diffused into the polymer network for further interactions ${ }^{48}$. Elovich and Intra-particle diffusion models were utilized to test the mechanism of the adsorption process. Elovich model was applied to designate the adsorption characteristics that concur with the nature of chemical adsorption $^{50}$. The linear fit between the $q_{t}$ versus $\ln t$ and $R^{2}$ for the Elovich kinetic model show that the dye removal kinetics can be explained by Elovich equation. In addition, it is concluded from data in Table 6, that the calculated $q_{e}$ were identical to experimental $q_{e}$. These results confirm that the studied biosorption system is controlled by chemisorption
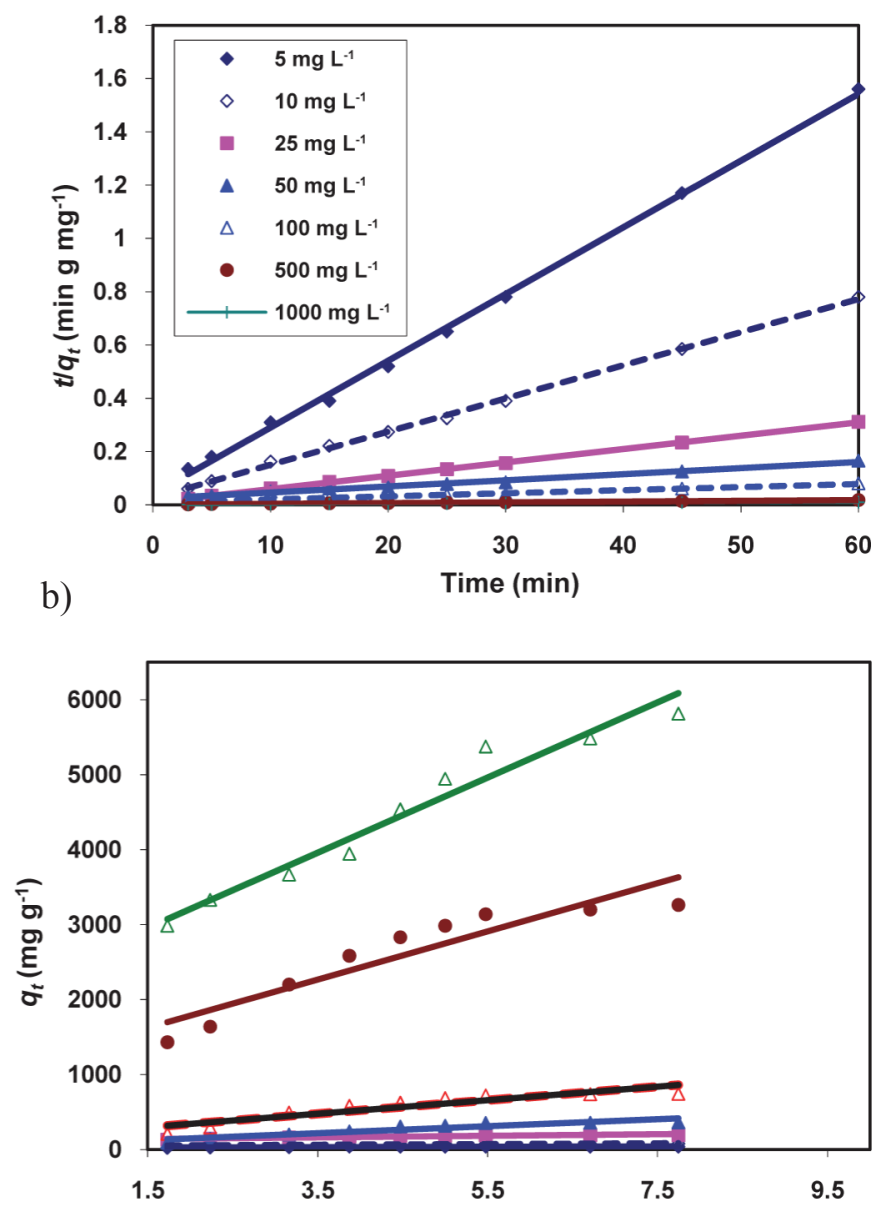

d)

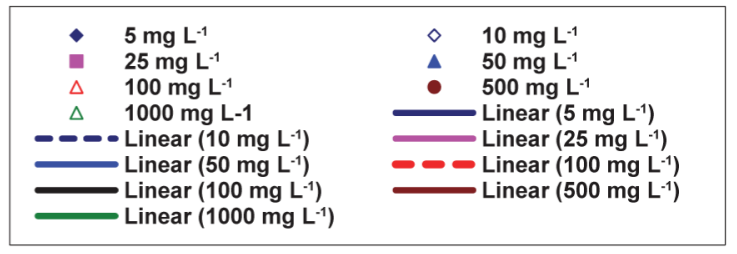

process. Moreover, it can be seen from the kinetics constants obtained from the Elovich equation (Table 6 ) that the value of $\alpha$ and $\beta$ vary as function of the initial dye concentration. Finally, the probability of intra-particle diffusion resistance influencing the dye biosorption was explored by using the intra-particle diffusion model. Figure 8 shows the amount of dye adsorbed versus $t^{1 / 2}$ for intra-particle transport of BY28 by 40B biopolymer adsorbent at different initial dye concentrations. The results show that the plots presented a multi-linearity, which indicated that two or more steps occurred in the process. The $R^{2}$ values for this diffusion model were between 0.978 and 0.997 , suggesting that the biosorption process can be followed by an intra-particle diffusion model. It can also be observed that the plots did not pass through the origin, this was revealing about some degree of boundary layer mechanism, and this further showed that the intra-particle diffu- 
Table 6 - Kinetic parameters of dye adsorption on $40 B$ isolated biopolymer at different dye concentrations

\begin{tabular}{|c|c|c|c|c|c|c|c|c|c|c|c|c|c|c|}
\hline \multirow{2}{*}{$\begin{array}{c}\text { Kinetic model } \\
\text { Dye } \\
\begin{array}{c}\text { concentration } \\
\left(\mathrm{mg} \mathrm{L}^{-1}\right)\end{array}\end{array}$} & \multirow{2}{*}{$\begin{array}{c}\left(q_{e}\right)_{\exp } \\
\left(\mathrm{mg} \mathrm{g}^{-1}\right)\end{array}$} & \multicolumn{3}{|c|}{ Pseudo first-order } & \multicolumn{3}{|c|}{ Pseudo second-order } & \multicolumn{4}{|c|}{ Elovich model } & \multicolumn{3}{|c|}{ Intra-particle diffusion } \\
\hline & & $\begin{array}{c}\left(q_{e}\right)_{\mathrm{cal}} \\
\left(\mathrm{mg} \mathrm{g}^{-1}\right)\end{array}$ & $\begin{array}{c}K_{1} \\
\left(\min ^{-1}\right)\end{array}$ & $R^{2}$ & $\begin{array}{c}\left(q_{e}\right)_{\mathrm{cal}} \\
\left(\mathrm{mg} \mathrm{g}^{-1}\right)\end{array}$ & $\begin{array}{c}K_{2} \\
\left(\mathrm{~g} \mathrm{mg}^{-1}\right. \\
\left.\mathrm{min}^{-1}\right)\end{array}$ & $R^{2}$ & $\begin{array}{c}\left(q_{e}\right)_{\mathrm{cal}} \\
\left(\mathrm{mg} \mathrm{g}^{-1}\right)\end{array}$ & $\begin{array}{c}\alpha \\
\left(\mathrm{mg} \mathrm{g}^{-1}\right. \\
\left.\min ^{-1}\right)\end{array}$ & $\begin{array}{c}\beta \\
\left(\mathrm{mg} \mathrm{g}^{-1}\right. \\
\left.\min ^{-1}\right)\end{array}$ & $R^{2}$ & $\begin{array}{c}K_{i d} \\
\left(\mathrm{mg} \mathrm{g}^{-1}\right. \\
\left.\min ^{-1}\right)\end{array}$ & $I$ & $R^{2}$ \\
\hline 5 & & 33.58 & & & 38.52 & 0.264 & 0.9985 & 37.2 & 19.2 & 5.5 & & 2.4 & 23.8 & 0.9 \\
\hline 10 & 76.9 & 62.8 & 0.128 & 0.924 & 76.7 & 0.347 & 0.9991 & 77.3 & 40.3 & 10.1 & & 4.6 & 47.5 & 0.98 \\
\hline 25 & 191.58 & 118.9 & 0.1309 & 0.904 & 191.72 & 0.278 & 0.9995 & 190.8 & 108.7 & 22.8 & 0.987 & 10.5 & 125.1 & 0.99 \\
\hline 50 & 353.84 & 387.5 & 0.091 & 0.934 & 353.44 & 0.221 & 0.9987 & 352.94 & 13 & 98.8 & 0.998 & 46.9 & 153.1 & 0.97 \\
\hline 100 & 721.54 & 658.88 & 0.1138 & 0.911 & 721.14 & 0.283 & 0.9994 & 722.2 & 20.6 & 194.3 & 0.995 & 90.3 & 160.1 & 0.99 \\
\hline 500 & 3138.46 & 3227.9 & 0.113 & 0.9 & 3137.9 & 0.275 & 0.9993 & 3135.2 & 678.9 & 679.9 & 0.993 & 321 & 1144.1 & 0.9 \\
\hline 1000 & 5376.92 & 5125.9 & 0.0829 & 0.91 & 5377 & 0.153 & 0.9989 & 5372.1 & 1643.7 & 1002.5 & 0.986 & 500.8 & 2200.3 & 0.99 \\
\hline
\end{tabular}

sion mechanism was not the only rate-limiting step, but other processes might control the rate of biosorption. The slope of the linear portion recorded the rate factor corresponding to the intra-particle diffusion (the values for each initial concentration are given in Table 6). It was found that both the rate constant and the thickness of the boundary layer were incremented with improving dye concentration $^{49}$

\section{Conclusions}

The biosorption of basic yellow 24 (BY24) from aqueous solutions onto three different innovative Egyptian isolated and purified bioflocculants, namely 32A, 38A, 40B, was affected by many processing parameters, such as the initial dye concentrations, solution temperature, and initial solution $\mathrm{pH}$. The results of biosorption process show that their purified biopolymers can be effectively used as a biosorbent for the basic dyes removal. The 40B biosorbent exhibited the highest sorption capacities toward BY24 compared with the remaining two biopolymers. The equilibrium dye sorption data were examined by the Langmuir, Freundlich, and Temkin isotherms, and the distinguishing parameters for each isotherm were determined. The results showed that the experimental data correlated reasonably well with the Langmuir and Temkin isotherms. This gives prediction that the batch biosorption process may be identified as a single-stage equilibrium operation. The kinetic studies of BY24 sorption onto purified 40B biopolymer as the most efficient one were performed based on pseudo first-order, pseudo second-order, Elovich, and intra-particle diffusion rate mechanisms. The data indicated that the biosorption kinetics of dye followed the pseudo second-order model at different dye concentrations and the intra-particle diffusion was not the only rate-limiting step. Moreover, the negative values of both the enthalpy and the free energy change indicated the exothermic and spontaneous characteristics of the biosorption process, respectively. Finally, on the basis of the present investigation results, the three isolated and purified biopolymers represent eco-friendly biosorbent materials for dye removal from coloured industrial wastewater.

\section{ACKNOWLEDGMENTS}

This work was supported by a grant from the Egyptian Science and Technology Development fund (STDF) (Grant No. 743). The authors are deeply grateful to City of Scientific Research and Technological Applications (SRTA-City) in Egypt for supporting this study and covering the costs to publish in open access.

\section{AUTHOR CONTRIBUTIONS}

Marwa Elkady and Desouky Abd-El-Haleem conceived and designed the experiments, Sahar Zaki and Soha Farag performed the experiments, Marwa Elkady and Desouky Abd-El-Haleem analysed the data, Sahar Zaki and Soha Farag contributed reagents/materials/analysis tools, all authors contributed at writing the paper.

\section{CONFLICTS OF INTEREST}

The authors declare no conflict of interest.

\section{References}

1. Vinod, K., Rajeev, J., Alok, M., Tawfik, A., Saleh, A., Nayak, S., Agarwal, S., Shalini, S., Photo-catalytic degradation of toxic dye amaranth on $\mathrm{TiO}_{2} / \mathrm{UV}$ in aqueous suspensions, Mater. Sci. Eng. 32 (2012) 12.

doi: https://doi.org/10.1016/j.msec.2011.08.018 
2. Alok, M., Dipika, K., Arti, M., Jyoti, M., Gupta V., Adsorption studies on the removal of coloring agent phenol red from wastewater using waste materials as adsorbents, J. Colloid Interface Sci. 337 (2009) 345.

doi: https://doi.org/10.1016/j.jcis.2009.05.016

3. Elkady, M. F., Shokry Hassan, H., Equilibrium and dynamic profiles of azo dye sorption onto innovative nano-zinc oxide biocomposite, Curr. Nanosci. 11 (2015) 805. doi: https://doi.org/10.2174/1573413711666150415003115

4. Tim, R., Geo, M., Roger, M., Poonam N., Remediation of dyes in textile effluent: a critical review on current treatment technologies with a proposed alternative, Bioresour. Technol. 77 (2001) 247. doi: https://doi.org/10.1016/S0960-8524(00)00080-8

5. Jawad, A. H., Alkarkhi,, F. M., Abdul, N. S., Photocatalytic decolorization of methylene blue by an immobilized $\mathrm{TiO}_{2}$ film under visible light irradiation: optimization using response surface methodology (RSM), Desalination Water Treat. 56 (2015) 161. doi: https://doi.org/10.1080/19443994.2014.934736

6. Jawad, A. H., Mubarak, N. A., Ishak, M. A., Ismail, K., Nawawia, W. I., Kinetics of photocatalytic decolourization of cationic dye using porous $\mathrm{TiO}_{2}$ film, Journal of Taibah University for Science 10 (2016) 352. doi: https://doi.org/10.1016/j.jtusci.2015.03.007

7. Elkady, M. F., Hassan, H. S., Hafez, E. E., Fouad, A., Construction of zinc oxide into different morphological structures to be utilized as antimicrobial agent against multidrug resistant bacteria, Bioinorg. Chem. Appl. 2015 (2015) 1. doi: https://doi.org/10.1155/2015/536854

8. Gupta, K., Shilpi, A., Saleh A., Synthesis and characterization of alumina-coated carbon nanotubes and their application for lead removal, J. Hazardous Mater. 185 (2011) 17. doi: https://doi.org/10.1016/j.jhazmat.2010.08.053

9. Jawad, A. H., Abd Rashid, R., MohdIshak, M. A, Wilson, L. $D$., Adsorption of methylene blue onto activated carbon developed from biomass waste by $\mathrm{H}_{2} \mathrm{SO}_{4}$ activation: kinetic, equilibrium and thermodynamic studies, Desalination Water Treat. 57 (2016) 25194.

doi: https://doi.org/10.1080/19443994.2016.1144534

10. Jawad, A. H., Abd Rashid, R., Roweda, M. A., MohdIshak, M. M., Kasim, N. N., Ismail, K., Adsorption of methylene blue onto coconut (Cocos nucifera) leaf: optimization, isotherm and kinetic studies, Desalination Water Treat. 57 (2016) 8839 . doi: https://doi.org/10.1080/19443994.2015.1026282

11. Hai, F. I., Yamamoto, K., Fukushi, K., Hybrid treatment systems for dye wastewater, Crit. Rev. Env. Sci. Technol. 37 (2007) 315. doi: https://doi.org/10.1080/10643380601174723

12. Elkady, M, Shokry, H., Effect of superparamagnetic nanoparticles on the physicochemical properties of nano hydroxyapatite for groundwater treatment: adsorption mechanism of Fe(II) and Mn(II), RSC Adv. 6 (2016) 82244. doi: https://doi.org/10.1039/C6RA14497G

13. Gadallah, A., Sahar, Z., Soha, F., Marwa, E., Desouky, A., Exobiopolymer from polyhydroxyalkanoate-producing transgenic yeast, Afr. J. Biotechnol. 10 (2011) 6558. doi: https://doi.org/10.5897/AJB11.245

14. Elkady, M. F., Hassan, H. S., Invention of hollow zirconium tungesto- vanadate at nanotube morphological structure for radionuclides and heavy metal pollutants decontamination from aqueous solutions, Nanoscale Res. Lett. 10 (2015) 1 .

doi: https://doi.org/10.1186/s11671-015-1180-0
15. Sahar, Z., Marwa, E., Desouky A., Biosynthesis and structural characterization of silver nanoparticles from bacterial isolates, Mat. Res. Bull. 46 (2011)1571. doi: https://doi.org/10.1016/j.materresbull.2011.06.025

16. Zaki, S. A., Elkady, M. F., Farag, S., Abd-El-Haleem, D. M., Characterization and flocculation properties of a carbohydrate bioflocculant from a newly isolated Bacillus velezensis 40B, J. Env. Biol. 34 (2013) 51.

17. Elkady, M. F., Farag, S., Zaki, S. A., Abu-Elreesh, G., AbdEl-Haleem, D. M., A Bacillus mojavensis strain 32A, a bioflocculant-producing bacterium isolated from an Egyptian salt production pond, Bioresour. Technol. 102 (2011) 8143 doi: https://doi.org/10.1016/j.biortech.2011.05.090

18. Farag, S., Zaki, S., Elkady, M. F., Abd-El-Haleem, D., Production and characteristics of a bioflocculant produced by Pseudomonas sp. strain 38A, J. Adv. Biol. 4 (2014) 286. doi: https://doi.org/med/24006807

19. Bradford, M., A Rapid and sensitive method for the quantitation of microgram quantities of protein utilizing the principle of protein-dye binding, Analyt. Biochem. 72 (1976) 248 .

doi: https://doi.org/10.1016/0003-2697(76)90527-3

20. Elkady, M. F., El-Aassar, R., Shokry Hassan, H., Adsorption profile of basic dye onto novel fabricated carboxylated functionalized co-polymer nanofibers, Polymers 177 (2016) 1. doi: https://doi.org/ 10.3390/polym8050177

21. Abd-El-Haleem, D., Zaki, S., Use of bioluminescent indicator Acinetobacter bacterium for screening and characterization of active antimicrobial agents, J. Microbiol. Biotechnol. 16 (2006) 1706.

22. Langmuir, I., The adsorption of gases on plane surfaces of glass, mica and platinum, J. Am.Chem. Soc. 40 (1918) 1361. doi: https://doi.org/10.1021/ja02242a004

23. Elkady, M. F., EL-Sayed, E., Farag, H., Zaatout, A., Assessment of novel synthetized nanozirconium tungstovanadate as cation exchanger for lead ion decontamination, $\mathrm{J}$ Nanomater. 2014 (2014) 1 doi: https://doi.org/10.1155/2014/149312

24. Temkin, M. I., Pyzhev, V., Kinetics of ammonia synthesis on promoted iron catalysts, Acta Physicochima USSR. 12 (1940) 327.

25. Elkady, M. F., Hassan, H. S., El-Sayed, E., Basic violet decolourization using alginate immobilized nano-zirconium tungestovanadate matrix as cation exchanger, J. Chem. 2015 (2015) 1. doi: https://doi.org/ 10.1155/2015/385741

26. Lagergren, S., Zurtheorie der sogenannten adsorption gel`sterstoffe, Kungliga Suensk Vetenskapsakademiens Handlingar 241 (1898) 1

27. Abd El-Latif, M. F., Elkady, M. F., Synthesis, characterization and evaluation of nano-zirconium vanadate ion exchanger by using three different preparation techniques, Mater. Res. Bull. 46 (2011) 105. doi: https://doi.org/10.1016/j.materresbull.2010.09.032

28. Hassan, H. S., Elkady, M. F., El-Shazly, A., Hesham, B., Formulation of synthesized zinc oxide nanopowder into hybrid beads for dye separation, J. Nanomater. 2014 (2014) 1. doi: https://doi.org/ 10.1155/2014/967492

29. Ho, Y. S., McKay, G., Pseudo-second order model for sorption processes, Process Biochem. 34 (1999) 451. doi: https://doi.org/10.1016/S0032-9592(98)00112-5

30. Zaki, S., Farag, S., Abu-Elreesh, G., Elkady, M., Nosier, M. Abd-El-Haleem, D., Characterization of bioflocculants produced by bacteria isolated from crude petroleum oil, Int. J. Env. Sci. Tech. 8 (2011) 831. doi: https://doi.org/10.1007/BF03326198 
31. Saddeek, Shokry, H., AbdElfadeel, G., Fabrication and analysis of new bismuth borate glasses containing cement kiln dust, J. Non Cryst. Solids 403 (2014) 47. doi: https://doi.org/10.1016/j.jnoncrysol.2014.07.004

32. Kumar, K. V., Kumaran, A., Removal of methylene blue by mango seed kernel powder, Biochem. Eng. J. 27 (2005) 83. doi: https://doi.org/10.1016/j.bej.2005.08.004

33. Elkady, M., Shokry H., Hashim, A., Immobilization of magnetic nanoparticles onto amine-modified nano-silica gel for copper ions remediation, Materials 9 (2016) 460. doi: https://doi.org/10.3390/ma9060460

34. Xue, X., Li, F., Removal of $\mathrm{Cu}$ (II) from aqueous solution by adsorption onto functionalized SBA- 16 mesoporous silica, Microporous Mesoporous Mater. 116 (2008) 116. doi: https://doi.org/10.1016/j.micromeso.2008.03.023

35. Zhang, Z., Xiaa, S., Wanga, X., Yanga, A., Xua, B., Chena, L., Zhua, Z., Zhaoa, J., Jaffrezic-Renault, N., Leonard, D. A novel biosorbent for dye removal: Extracellular polymeric substance (EPS) of Proteus mirabilis TJ-1, J. Hazard. Mater. 163 (2009) 279. doi: https://doi.org/10.1016/j.jhazmat.2008.06.096

36. El-Aassar, M., El-Kady, M., Shokry, H., Al-Deyab, S., Synthesis and characterization of surface modified electrospun poly(acrylonitrile-co-styrene) nanofibers for dye decolorization, J. Taiwan Inst. Chem. 58 (2016) 272. doi: https://doi.org/10.1016/j.jtice.2015.05.042

37. Shaaban, E., Yasser, A., Ismail, Shokry, H., Compositional dependence of the optical properties of amorphous Se80 xTe20Bix thin films using transmittance and reflectance measurements, J. Non Cryst. Solids 376 (2013) 61. doi: https://doi.org/10.1016/j.jnoncrysol.2013.05.024

38. Kiran, S., Akar, T., Ozcan, A. S., Ozcan, A., Tunali, S., Biosorption kinetics and isotherm studies of Acid Red 57 by dried Cephalosporium aphidicola cells from aqueous solutions, Biochem. Eng. J. 31 (2006) 197. doi: https://doi.org/10.1016/j.bej.2006.07.008

39. Vijayaraghavan, K., Yun, Y. S., Biosorption of CI Reactive Black 5 from aqueous solution using acid-treated biomass of brown seaweed Laminaria sp., Dyes Pigm. 76 (2008) 726. doi: https://doi.org/10.1016/j.dyepig.2007.01.013

40. Mohy-Eldin, M. S., Elkady, M. F., Abu-Saied, M. A., Abdel Rahman, A. M., Soliman, E. A., Elzatahry, A. A., Youssef, M. E., Removal of cadmium ions from synthetic aqueous solutions using novel nano-sulphonated poly(glycidyl methacrylate) cation exchanger: Kinetic and equilibrium studies, J. Appl. Polym. Sci. 118 (2010) 3111. doi: https://doi.org/10.1002/app.32587
41. Crini, G., Badot, P. M., Application of chitosan, a natural aminopolysaccharide, for dye removal from aqueous solutions by adsorption processes using batch studies: A review of recent literature, Prog. Polym. Sci. 33 (2008) 399. doi: https://doi.org/10.1016/j.progpolymsci.2007.11.001

42. Hassan, H., Elkady, M., Hafez, E., Salama, E., Novel antibacterial zinc oxide polymeric nanocomposite membrane as wound dress, Nanosc. and Nanotech - Asia 7 (2017) 62. doi: https://doi.org/10.2174/2210681206666160609083249

43. Elkady, M., Abu-Saied, M., Abdel Rahman, A., Soliman, E., Elzatahry, A., Youssef, M., Mohy-Eldin, M., Nano-sulphonated poly (glycidylmethacrylate) cations exchanger for cadmium ions removal: effects of operating parameters, Desalination 279 (2011) 152. doi: https://doi.org/10.1016/j.desal.2011.06.002.

44. Ng, C., Losso, J. N., Marshall, W. E., Ra, R. M., Freundlich adsorption isotherms of agricultural by-product-based powdered activated carbons in a geosmin-water system, Bioresour. Technol. 85 (2002) 131. doi: https://doi.org/10.1016/S0960-8524(02)00093-7

45. Inbaraj, B. S., Chien, J. T., Ho, G. H., Yang, J., Chen, B. H., Equilibrium and kinetic studies on sorption of basic dyes by a natural biopolymer poly( $\gamma$-glutamic acid), Biochem. Eng. 31 (2006) 204. doi: https://doi.org/10.1016/j.bej.2006.08.001

46. Kalavathy, M., Karthikeyan, T., Rajgopal, S., Miranda, L., Kinetic and isotherm studies of $\mathrm{Cu}(\mathrm{II})$ adsorption onto $\mathrm{H}_{3} \mathrm{PO}_{4}$-activated rubber wood sawdust, J. Colloid Interface Sci. 292 (2005) 354. doi: https://doi.org/10.1016/j.jcis.2005.05.087

47. Ho, Y. S., Porter, J. F., McKay, G., Equilibrium isotherm studies for the sorption of divalent metal ions onto peat: Copper, nickel and lead single component systems, Water Air Soil Pollut. 141 (2002) 1. doi: https://doi.org/10.1023/A:1021304828010

48. SenthilKumar, P., Ramalingam, S., Sathyaselvabala, V., Dinesh Kirupha, S., Sivanesan, S., Removal of copper(II) ions from aqueous solution by adsorption using cashew nut shell, Desalination 266 (2011) 63. doi: https://doi.org/10.1016/j.desal.2010.08.003

49. Ho, Y. S., McKay, G., The kinetics of sorption of basic dyes from aqueous solution by sphagnum moss peat, Can. J. Chem. Eng. 76 (1998) 822. doi: https://doi.org/10.1002/cjce.5450760419

50. Juang, R. S., Chen, M. L., Application of the Elovich equation to the kinetics of metal sorption with solvent-impregnated resins, Ind. Eng. Chem. Res. 36 (1997) 813. doi: https://doi.org/10.1021/ie960351f 